\title{
Mild cognitive impairment and dementia in a heterogeneous elderly population: prevalence and risk profile
}

\author{
S Ramlall', J Chipps², BJ Pillay3, Al Bhigjee ${ }^{4}$ \\ ${ }^{1}$ Department of Psychiatry, College of Health Sciences, University of KwaZulu-Natal, Durban, South Africa \\ ${ }^{2}$ School of Nursing and Public Health, College of Health Sciences, University of KwaZulu-Natal, Durban, South Africa \\ ${ }^{3}$ Department of Behavioural Medicine, College of Health Sciences, University of KwaZulu-Natal, Durban, South Africa \\ ${ }^{4}$ Department of Neurology, College of Health Sciences, University of KwaZulu-Natal, Durban, South Africa
}

\begin{abstract}
Objective: To describe the demographic, clinical and risk profile of Mild Cognitive Impairment and dementia in a sample of elderly South Africans within a residential setting. Method: One hundred and forty participants residing in a group of residential homes for the elderly were assessed by psychiatrists and assigned diagnoses of dementia or Mild Cognitive Impairment (MCI). Participants diagnosed with dementia were also offered haematological investigations and a CT scan of the brain. Results: The sample consisted of 140 participants comprising 46.4\% White, 29.3\% Coloured, 20\% Asian and 4.3\% Black participants. There were 97 (69.3\%) females and 106 (75.7\%) participants had less than 12 years of education. Eleven (7.9\%) dementia and 38 (27.1\%) MCI cases were diagnosed. Increasing age was associated with cognitive impairment (MCI and dementia) ( $p=.020)$ but there was no association between gender and cognitive impairment $(\mathrm{p}=.165)$. MCI was significantly associated with a lower education level $(p=.036)$ and no association was found between depression (current- $\mathrm{p}=.646$; past- $\mathrm{p}=.719$ ) and dementia or MCI. The presence of vascular risk factors $(n=140$ ) ranged from 66.4\% (hypertension) to 14.3\% (stroke). Subjective memory complaints were significantly associated with cognitive impairment ( $p=.001)$. Except for the use of the telephone $(p=.225)$ and the television $(p=.08)$, impairment in all domains of instrumental activities of daily living that were assessed were significantly associated with a dementia diagnosis. Conclusion: The study showed that cognitive impairment was associated with increasing age and low education levels. The presence of vascular risk factors places this population at risk for future cognitive decline.
\end{abstract}

Keywords: Dementia; Mild cognitive impairment; Prevalence; Risk factors; South Africa

Received: 24-10-2012

Accepted: 16-01-2013

doi: http://dx.doi.org/10.4314/ajpsy.v16i6.58

\section{Introduction}

With the elderly population in lower and middle income countries (LAMIC) predicted to increase from 60\% in 2001 to $71 \%$ by 2040 , dementia rates are expected to increase between $100 \%$ to $300 \%$ in these regions. ${ }^{1}$ Dementia costs for Africa have been conservatively estimated to be in the region of US $\$ 2.9$ billion. ${ }^{2}$ To address this financial and clinical burden in lower and middle income countries, data on the local prevalence of dementia and its associated risk factors are important. In the absence of disease-modifying pharmacotherapeutic options, decreasing the prevalence of dementia may be achieved by modifying risk factors or lifestyle. ${ }^{3}$ Therefore the early

\section{Correspondence}

Dr S Ramlall

P.O. Box 65810, Reservoir Hills, Durban, 4090, South Africa

email: ramlalls4@ukzn.ac.za identification and management of risk factors and early diagnosis of dementia, can contribute to a reduction in the burden of disease and result in significant cost savings. ${ }^{4}$

While dementia is a huge public health challenge in high income countries (HIC), with high prevalence rates reported ${ }^{5,6}$, it appears that the prevalence may be lower in LAMIC. ${ }^{7}$ Large prevalence studies conducted in Nigeria ${ }^{8}$ and India ${ }^{9}$ reported figures of $2.29 \%$ and $0.84 \%$ respectively. In two large crosscountry studies, one comparing African and American Blacks ${ }^{8}$ and the other comparing rural populations from India and America ${ }^{9}$, it was found that the prevalence rates of dementia and Alzheimer's Dementia (AD) were significantly lower for participants in the lower income countries. Similar findings have emerged from prevalence studies in Latin America and China. ${ }^{7}$ The lower prevalence rates in LAMIC has also been confirmed in the Delphi consensus study suggesting that factors such as methodology, differential survival rates and/ or 
differences in the risk profile (low levels of cardiovascular risk and hypolipidaemia) in LAMIC populations may be contributing to the lower rates.

While the incidence and prevalence of dementia have been extensively studied in Western and European countries ${ }^{5}$ there remains a dearth of similar studies from Africa. The few studies conducted in Africa prior to 2000 used small samples and was reported to have used 'non-standardised clinical assessments'. ${ }^{10}$ Recent studies from Africa reported prevalence figures ranging from 2.6\% to $8.1 \% .^{11,12,13}$ Dementia studies from South Africa include a Western Cape sample of coloured people ${ }^{14}$, with a prevalence of $8.6 \%$, and a Free State sample of indigenous Sotho-speaking elderly black people ${ }^{15}$, which reported a prevalence of $7.7 \%$.

This paper describes the clinical and risk profile of a sample of elderly participants who were assessed for the presence of dementia and MCI. In addition, the value of functional assessments and subjective memory complaints in case-finding are also explored.

\section{Method}

The study consisted of three stages: 1) Administration of dementia screening tools; 2) Clinical diagnostic evaluation for dementia; and 3) Administration of a neuropsychological battery of tests.

\section{Sample}

The study population comprised residents ( $\mathrm{N}=1450)$ of a group of homes for the elderly in Durban, KwaZulu-Natal, South Africa. The homes are administered by a nongovernmental organisation (NGO) and cater for frail care, assisted and independent living people 60 years and older.

An initial conveniently selected sample ( $\mathrm{n}=302)$ was selected to undergo screening for cognitive impairment using the Mini-Mental State Examination (MMSE). Inclusion criteria were: residents who were 60 years and older, a minimum of 8 years of formal schooling, the ability to speak, read and write in English and the ability to give written, informed consent. Exclusion criteria were: residents with severe physical, mental or sensory handicaps that precluded their engagement in the assessment procedures.

This paper describes the results of the second stage of the study, the clinical diagnostic evaluation for dementia. The target population for this stage was 51 participants who screened positive $(<23)$ on the MMSE and a random selection of the 251 participants who screened negative. The resulting sample of 140 participants included 38 screen positives (13 either refused or were unavailable) and 102 screen negatives.

\section{Evaluations}

Clinical diagnostic evaluations were conducted in English by three psychiatrists, who were blinded to the results of the screening stage. A standardised clinical assessment tool was developed for the study. The assessment tool included the following sections: a historical review of the participant's cognitive status, a review of the medical, surgical, family, medication and substance use history, a review of social and functional activities, a physical (including neurological) examination and a comprehensive mental state examination. The assessment of functional abilities was based on participant self-report as the residential setting precluded access to informants. Participants were classified as being functionally unable to perform specified activities of daily living $(A D L)$ and instrumental activities of daily living (IADL) tasks only after medical causes for the inability were excluded. Content validity was based on the the Diagnostic and Statistical Manual, Fourth edition, Text Revised (DSM IV-TR) criteria for Dementia, Major Depression and Delirium. Face validity of the tool was established through review of the tool by a group of psychiatrists, neurologists and psychologists. Although the assessing psychiatrists underwent intensive training in order to standardise the assessments, inter-rater reliability was not formally established.

\section{Diagnosis}

Following the clinical diagnostic assessments, a consensus panel consisting of a senior neurologist, senior clinical psychologist and psychiatrist assigned diagnoses of dementia, major depression-current and delirium according to DSM IVTR criteria. ${ }^{16}$ Participants who did not fulfil the criteria for dementia or MCI were categorised as 'non-cases'. A DSM-IV$\mathrm{TR}^{16}$ diagnosis of dementia is based on, firstly, the development of multiple cognitive deficits manifested by both memory impairment as well as one of four areas (aphasia, apraxia, agnosia, executive functioning) of cognitive disturbances; and secondly, these cognitive deficits should also cause significant impairment in social or occupational functioning. ${ }^{16}$ Sub-typing of the dementias was not done. A diagnosis of Mild Cognitive Impairment (MCI) was based on the recommendations of the International Working Group on Mild Cognitive Impairment and requires the presence of subjective cognitive impairment (self or informant reported), objective evidence of cognitive impairment in the presence of high scores for ADL and normal or minimally-impaired IADL functions. ${ }^{17} \mathrm{MCI}$ diagnostic subtypes of amnestic MCI, single domain (aMCIsd), multi-domain (aMCImd) non-amnestic MCI single domain (naMCIsd) were based on the presence or absence of amnesia and the presence of single or multiple cognitive domains of impairment. ${ }^{18}$ Those participants who did not meet criteria for Dementia or MCI were classified as noncases.

\section{Investigations}

For ethical reasons, all participants who were assigned a clinical diagnosis of dementia were offered blood tests (full blood count [FBC], blood glucose, thyroid functioning test [TFT], syphilis serology [RPR] and Vitamin Bl2 and folate levels) as well as a CT scan of the brain, without contrast.

\section{Statistical Analysis}

The data was analysed according to diagnostic categories of dementia and MCI. Differences in age and education between the diagnostic groups were tested using Independent Samples Kruskall Wallis Tests. Associations between diagnostic categories and demographic variables, the presence of risk factors and retained functionality in IADL were tested using Pearsons' Chi square Test or Fisher Exact Tests (where sample sizes were small). Significance was set as $\mathrm{p}<.05$.

\section{Ethics}

The study received ethical approval from the Biomedical Research Ethics Committee of the University of KwaZulu-Natal 


\section{Results}

\section{Demographic details}

Of the 140 participants assessed, 97 (69.3\%) were female and $43(30.7 \%)$ were male. The average age of the participants was 75.2 years ( \pm 8.9). In South Africa, four racial groups are recognized viz Asian (Indian), black, coloured and white. There were 65 (46.4\%) white, 41 (29.3\%) coloured, 28 (20\%) Asian and 6 (4.3\%) black participants. Proficiency in English was an inclusion criterion for the study. It was the first language for 123 (87.9\%) of the participants, followed by Xhosa (7\%), then Afrikaans (4.3\%) and isiZulu (4.3\%), and other languages (2.9\%). Eleven (7.9\%) participants had more than 12 years of education and 106 (75.7\%) had less than 12 years of education.

Most participants (132, 94.3\%) were in independent living residences with seven (5\%) in assisted living. One hundred and four (72.9\%) reported that they lived alone and 32 (22.9\%) were either living together or married. A government pension was the sole source of income for ninety-seven (69.3\%) participants. The demographic data according to the diagnostic categories are presented in Table I. Significant associations were found between the diagnostic categories and the mean age and mean years of education of the participants.

\section{Clinical diagnostic categories}

Eleven (7.9\%) cases of dementia and 38 (27.1\%) cases of mild cognitive impairment (MCI) were diagnosed, with 91 (61\%) participants not meeting criteria for dementia or MCI (noncases).

Six of the 11 participants who were diagnosed with dementia agreed to have blood tests performed, and no abnormalities were detected apart from elevated blood glucose in two participants who were known sufferers of diabetes mellitus. Of the 11 participants, four new CT scans, one previously done CT and one previously done MRI scan were reviewed with all scans revealing evidence of vascular pathology in the brain, with evidence of old infarcts in three of the CT scans.
Of the 38 cases of MCI, 18(47.4\%) represented amnestic $\mathrm{MCI}$, single domain (aMCIsd), 12 (31.6\%) were amnestic MCI, multi-domain (aMCImd) and 8 (21.0\%) were non-amnestic MCI single domain (naMCIsd). No cases of non-amnestic MCI multiple domain (naMCImd) were identified. No cases of delirium were identified and thirteen participants (9.3\%) were diagnosed with major depression.

The 91 non-cases comprised a mixture of participants with varying degrees of cognitive and functional impairment. Impairment in executive functioning was present in 28 (30.8\%) and memory impairment in 36 (39.6\%) of these participants. Twenty of the 9l(22.0\%) would have met the criteria for MCI but were significantly functionally impaired in at least one instrumental activity of daily living domain and were therefore excluded; 17 of the 91(18.7\%) who were functionally impaired failed to meet the cognitive impairment criteria for dementia.

\section{Risk factor profile}

To establish a risk profile, the prevalence of clinical factors was determined for each diagnostic category and compared to 'non-cases' (Table II).

A number of significant associations between risk factors and diagnostic categories were found. Firstly, there were significant associations between the diagnostic groups and self-reported "blackouts" (transient periods of loss of consciousness for which a medical diagnosis had not been established at the time of assessment). Only $8.8 \%$ of non-cases reported a history of blackouts compared to $27.3 \%$ of participants with dementia and $26.3 \%$ of participants with MCI $(\mathrm{p}=.012)$

Secondly, a significant negative association was found between reported high blood pressure and cognitive impairment (dementia and MCI). Seventy three point six percent of non-cases reported a history of high blood pressure compared to $36.4 \%$ of participants with dementia and $57.9 \%$ of participants with MCI ( $\mathrm{p}=.024)$.

Thirdly, a significant association with exercise was found with participants with dementia reporting more engagement in

\section{Table I: Demographics according to Diagnostic Categories}

\begin{tabular}{|c|c|c|c|c|c|}
\hline Item & $\begin{array}{l}\text { Dementia } \\
(n=11) \\
n(\%)\end{array}$ & $\begin{array}{l}\mathrm{MCl} \\
(n=38) \\
n(\%)\end{array}$ & $\begin{array}{l}\text { Non-cases } \\
(n=91) \\
n(\%)\end{array}$ & Statistic & $P$ \\
\hline $\begin{array}{l}\text { Race } \\
\text { Asian } \\
\text { Black } \\
\text { Coloured } \\
\text { White }\end{array}$ & $\begin{array}{l}0(0 \%) \\
1(9.1 \%) \\
1(9.1 \%) \\
9(81.8 \%)\end{array}$ & $\begin{array}{l}6(15.8 \%) \\
2(5.3 \%) \\
15(39.5 \%) \\
15(39.5 \%)\end{array}$ & $\begin{array}{l}22(24.2 \%) \\
3(3.3 \%) \\
25(27.5 \%) \\
41(45.1 \%)\end{array}$ & $X^{2}=15.0$ & .078 \\
\hline $\begin{array}{l}\text { Gender } \\
\text { Female } \\
\text { Male }\end{array}$ & $\begin{array}{l}9(81.8 \%) \\
2(18.2 \%)\end{array}$ & $\begin{array}{l}30(78.9 \%) \\
8(21.1 \%)\end{array}$ & $\begin{array}{l}58(63.7 \%) \\
33(36.3 \%)\end{array}$ & $x^{2}=3.7$ & .165 \\
\hline Age & $77.2 \pm 7.9$ & $75.8 \pm 8.1$ & $72.1 \pm 6.8$ & $K=7.9$ & $.020^{*}$ \\
\hline Years of education & $10.3 \pm 2.6$ & $9.3 \pm 1.6$ & $10.3 \pm 2.1$ & $K=6.6$ & $.036^{*}$ \\
\hline
\end{tabular}


Table II: Presence of Risk Factors within Diagnostic Categories

\begin{tabular}{|c|c|c|c|c|c|c|}
\hline & $\begin{array}{l}\text { Dementia } \\
(n=11)\end{array}$ & $\begin{array}{l}\mathrm{MCl} \\
(n=38)\end{array}$ & $\begin{array}{l}\text { Non-cases } \\
(N=91)\end{array}$ & $\begin{array}{l}\text { Total } \\
(n=140)\end{array}$ & $X^{2}$ & P value \\
\hline $\begin{array}{l}\text { Vascular Risk Factors } \\
\text { Stroke } \\
\text { Blackouts } \\
\text { High Cholesterol } \\
\text { High blood pressure } \\
\text { Heart attack } \\
\Vdash \text { DD/Angina } \\
\text { Modified Hachinski score category }>=5\end{array}$ & $\begin{array}{l}4(36.4 \%) \\
3(27.3 \%) \\
3(27.3 \%) \\
4(36.4 \%) \\
0(0 \%) \\
3(27.3 \%) \\
3(27.3 \%)\end{array}$ & $\begin{array}{l}6(15.8 \%) \\
10(26.3 \%) \\
11(28.9 \%) \\
22(57.9 \%) \\
5(13.2 \%) \\
12(31.6 \%) \\
3(7.9 \%)\end{array}$ & $\begin{array}{l}10(11 \%) \\
8(8.8 \%) \\
30(33 \%) \\
67(73.6 \%) \\
21(23.1 \%) \\
22(24.2 \%) \\
7(7.7 \%)\end{array}$ & $\begin{array}{l}20 \text { (14.3\%) } \\
21(15 \%) \\
44(31.4 \%) \\
93(66.4 \%) \\
26(18.6 \%) \\
37(26.4 \%) \\
13(9.3 \%)\end{array}$ & $\begin{array}{l}X^{2}=4.8 \\
X^{2}=8.0 \\
X^{2}=0.3 \\
X^{2}=7.8 \\
X^{2}=4.1 \\
X^{2}=0.9 \\
X^{2}=4.5\end{array}$ & $\begin{array}{l}.065 \\
.012^{\star} \\
.879 \\
.024^{\star} \\
.117 \\
.649 \\
.120\end{array}$ \\
\hline $\begin{array}{l}\text { Lifestyle Risk Factors } \\
\text { Cigarettes Current or Past } \\
\text { Alcohol Current or Past } \\
\text { Engages in any exercise }\end{array}$ & $\begin{array}{l}8(72.7 \%) \\
7(63.6 \%) \\
6(54.5 \%)\end{array}$ & $\begin{array}{l}24(63.2 \%) \\
18(47.4 \%) \\
6(15.8 \%)\end{array}$ & $\begin{array}{l}75(82.4 \%) \\
35(38.5 \%) \\
22(24.2 \%)\end{array}$ & $\begin{array}{l}107(76.4 \%) \\
60(42.9 \%) \\
34(24.3 \%)\end{array}$ & $\begin{array}{l}X^{2}=1.7 \\
x^{2}=0.5 \\
X^{2}=7.0\end{array}$ & $\begin{array}{l}.795 \\
.833 \\
.031^{\star}\end{array}$ \\
\hline $\begin{array}{l}\text { Psychological Risk Factors } \\
\text { MDD Current } \\
\text { MDD Past }\end{array}$ & $\begin{array}{l}1(9.1 \%) \\
2(18.2 \%)\end{array}$ & $\begin{array}{l}2(5.3 \%) \\
12(31.6 \%)\end{array}$ & $\begin{array}{l}10(11 \%) \\
24(26.4 \%)\end{array}$ & $\begin{array}{l}13(9.3 \%) \\
38(27.1 \%)\end{array}$ & $\begin{array}{l}X^{2}=1.0 \\
X^{2}=.8\end{array}$ & $\begin{array}{l}.646 \\
.719\end{array}$ \\
\hline $\begin{array}{l}\text { \#Presence of at least one Subjective } \\
\text { Memory Complaint (SMCC) }\end{array}$ & 10 (90.9 \%) & 38 (100 \%) & 32 (35.2 \%) & 80 (57.1\%) & $X^{2}=51.6$ & $.001^{*}$ \\
\hline $\begin{array}{l}\text { Other Risk Factors } \\
\text { Family Dementia } \\
\text { Head injury } \\
\text { Diabetes Mellitus }\end{array}$ & $\begin{array}{l}0(0 \%) \\
1(9.1 \%) \\
4(36.4 \%)\end{array}$ & $\begin{array}{l}4(10.5 \%) \\
9(23.7 \%) \\
8(21.1 \%)\end{array}$ & $\begin{array}{l}7(7.7 \%) \\
16(17.6 \%) \\
25(27.5 \%)\end{array}$ & $\begin{array}{l}11(7.9 \%) \\
26(18.6 \%) \\
37(26.4 \%)\end{array}$ & $\begin{array}{l}X^{2}=1.3 \\
X^{2}=1.2 \\
X^{2}=1.2\end{array}$ & $\begin{array}{l}.687 \\
.535 \\
.530\end{array}$ \\
\hline
\end{tabular}

All risk factors were compared using Independent Samples Pearson Chi-square Tests and Fisher Exact Tests. *Significance level set as p <.05. \#SMCC was defined for a specified minimum duration (previous one year), frequency (at least once a week) and sub-type (memory for names, places, events).

physical exercise (54.5\%) compared to participants with MCI (15.8\%) and non-cases (24.2\%; $\mathrm{p}=.012)$.

Lastly, there was a significant association between the presence of a subjective memory complaint assessed clinically (SMCC) and the presence of dementia. Ninety point nine percent of participants with dementia compared to $35.2 \%$ of non-cases $(p<.001)$ reported the presence of an SMCC.

(SMCC is a diagnostic criterion for MCI). The presence of a SMCC was not significantly associated with the presence of major depression $\left(X^{2}=0.86, p=.355\right)$.

\section{Physical and functional impairment profile}

In addition to clinical risk factors, the presence of physical impairment (Table III) and the capacity to perform instrumental activities of daily living (Table IV) and diagnostic categories were also compared. Two significant associations were found between physical impairments and diagnostic groupings (Table III)

In terms of visual impairments, more participants with MCI reported visual impairments (92.1\%) as compared to participants with dementia (54.5 p=.019). More participants with dementia (45.5\%) and $\mathrm{MCI}(47.4 \%)$ also reported hearing impairments as compared to non-cases. (25.3\%; $\mathrm{p}=.036)$.

The ability to perform ADLs and IADLs have diagnostic significance for dementia. In evaluating the functional profile of participants, significant differences were found between dementia, MCI and non-cases for the following activities: Use of public transport, meal preparation, taking medication,

Table III: Presence of Physical Impairments within Diagnostic Categories

\begin{tabular}{|l|l|l|l|l|l|l|}
\hline & $\begin{array}{l}\text { Dementia } \\
(n=11)\end{array}$ & $\begin{array}{l}\text { MCl } \\
(n=38)\end{array}$ & $\begin{array}{l}\text { Non-cases } \\
(\text { N=91 })\end{array}$ & $\begin{array}{l}\text { Total } \\
(n=140)\end{array}$ & $X^{2}$ \\
\hline Uses walking aid & $4(36.4 \%)$ & $11(28.9 \%)$ & $23(25.3 \%)$ & $38(27.1 \%)$ & $X^{2}=0.7$ & .686 \\
Visual problems & $6(54.5 \%)$ & $35(92.1 \%)$ & $72(79.1 \%)$ & $113(80.7 \%)$ & $X^{2}=7.8$ & $.019^{*}$ \\
Use of visual aids & $6(54.5 \%)$ & $33(86.8 \%)$ & $77(84.6 \%)$ & $116(82.9 \%)$ & $X^{2}=5.7$ & .051 \\
Hearing problems & $5(45.5 \%)$ & $18(47.4 \%)$ & $23(25.3 \%)$ & $46(32.9 \%)$ & $X^{2}=6.8$ & $.036^{*}$ \\
Use of hearing aids & $2(18.2 \%)$ & $1(2.6 \%)$ & $5(5.5 \%)$ & $8(5.7 \%)$ & $X^{2}=3.4$ & .178 \\
\hline
\end{tabular}

All risk factors were compared using Independent Samples Pearson Chi-square Tests and Fisher Exact Tests. *Significance level set as p <.05. \#SMCC was defined for a specified minimum duration (previous one year), frequency (at least once a week) and sub-type (memory for names, places, events). 
shopping, and using the microwave and washing machine (Table IV). All participants reported being able to use a radio.

\section{Discussion}

\section{Prevalence of Dementia and MCI}

Dementia prevalence: The study identified a dementia prevalence of $7.9 \%$, similar to prevalence rates reported in homogeneous South African populations (8.6\%14 and 7.7\% $\%^{15}$ ) but greater than the mean age-adjusted prevalence estimate for dementia in LAMIC of 5.3\%. ${ }^{3}$ The range of prevalence figures in Africa could be attributed to differences in population age structures, genetics and lifestyle ${ }^{3}$, but could also be due to methodological factors in the assessment and assignment of a diagnosis. Methodological factors may include variations in the use of accurate, standardised diagnostic measures and variations in clinical opinion of what constitutes 'significant' impairment in social and occupational functioning. 'Impairment' also varies according to cultural expectations of the elderly with regard to their functional activities and hence influences the definition of 'functional impairment' in different socio-cultural settings. ${ }^{3}$

While our prevalence figure lies within the range reported for LAMIC countries, our sample is drawn from a residential, not a community or a nursing home setting . International prevalence figures for dementia in elderly residential homes vary from 36.7\%-58\%. 19,27,20,21,22 Prevalence figures vary according to the admission criteria and the heterogeneity in the types of residential facilities and data from LAMIC are scarce. In the United Kingdom, where almost $5 \%$ of people aged 65 years or older live in institutions, two thirds of the elderly in residential homes ${ }^{23}$ and $62 \%$ of the elderly residing in private and council residential and nursing homes were found to have dementia. ${ }^{24}$ The prevalence of dementia in Mexican nursing homes is $16.1 \% .{ }^{25,27}$

An important factor emerging from our study was that none of these residents had been previously diagnosed with dementia or MCI. The under-recognition of dementia is not unique to our setting as rates of under-recognition range from $31.8 \%{ }^{21}$ for dementia in Scotland to $70 \%$ for mild dementia in Hong Kong. ${ }^{20}$ Our findings therefore identify a need for increasing the awareness of dementia among the personnel working in residential settings for the elderly.

A limitation in our findings has been the exclusion of those unable or too impaired to engage consensually in the assessment procedures and this may have contributed to the relatively low prevalence of dementia of $7.9 \%$ in our study. Further large scale community studies are needed to confirm the prevalence of dementia in South Africa.

MCI prevalence: MCI was diagnosed in $27 \%$ of our sample, which is similar to the prevalence rates of $3 \%$ to $42 \%{ }^{26}$ reported in the literature. The wide range has been attributed to the lack of standardization of the definition and diagnostic criteria of MCI. ${ }^{26}$ Diagnostic consistency across studies will assist in establishing the true burden posed by MCI in the elderly. This is important as the reported annual conversion rate of MCI to Alzheimer's dementia is $10-15 \%{ }^{27}$ in high risk clinical populations and $4.2 \%$ in the general population. ${ }^{28}$

Despite existing diagnostic criteria for $\mathrm{MCI}^{27,29}$, the lack of appropriate and sensitive neuropsychological and functional measure ${ }^{30}$ poses challenges to its consistent application and interpretation. Challenges in assigning this diagnosis include the fact that subjective memory deficits lack clear definition ${ }^{31}$, and the interpretation of what constitutes 'minimal' impairment in IADL in the context of MCI. This is important as it has been shown that impairment in IADL impacts significantly on the prognostic value of $\mathrm{MCI}$ with respect to progression to dementia. ${ }^{32-35}$ Delaying the progression of MCI to dementia by one year will result in significant cost savings ${ }^{36}$, therefore objective measurement criteria for MCI and IADL are essential.

The most prevalent subtypes of MCI in our study was aMCIsd (47.4\%) followed by aMCImd (31.6\%). The risk of converting to dementia is increased when cognitive domains in addition to memory (multi-domain) are impaired. ${ }^{37}$ Those with single domain MCI are reported to revert to normal cognitive functioning with greater frequency than those with multidomain impairment. ${ }^{28}$ This places almost a third of those diagnosed with MCI in our sample at high risk for progressing to dementia and targets them for close monitoring. However, although MCI subtypes have diagnostic validity and clinical utility $^{38,28}, \mathrm{MCI}$ is a heterogeneous condition ${ }^{39}$ both aetiologically and prognostically and the clinical significance of these subtypes are best evaluated in a prospective study.

Challenges in the evaluation of cognition: The evaluation of cognition in the elderly, especially in in LAMICs, is compounded by numerous practical and technical issues. ${ }^{40,41} \mathrm{~A}$ major challenge is the validity and sensitivity of the diagnostic criteria applied. Diagnostic criteria should help to clearly distinguish normal from pathological cognitive impairment.

Table IV: Retained Functionality in IADL

\begin{tabular}{|c|c|c|c|c|c|c|}
\hline & $\begin{array}{l}\text { Dementia } \\
(n=11)\end{array}$ & $\begin{array}{l}\mathrm{MCl} \\
(n=38)\end{array}$ & $\begin{array}{l}\text { Non-cases } \\
(\mathrm{N}=91)\end{array}$ & $\begin{array}{l}\text { Total } \\
(n=140)\end{array}$ & $X^{2}$ & P value \\
\hline Telephone use & $10(90.9 \%)$ & $38(100 \%)$ & $88(96.7 \%)$ & $136(97.1 \%)$ & $X^{2}=2.7$ & .225 \\
\hline Public transport ( ${ }^{\star} \mathrm{NA}=15$ ) & $4(40 \%)$ & $33(100 \%)$ & 78 (95.1\%) & $115(89.3 \%)$ & $x^{2}=22.3$ & $<.001^{\star}$ \\
\hline Meal preparation (NA=7) & $8(80 \%)$ & $34(97.1 \%)$ & 87 (98.9\%) & $129(92.1 \%)$ & $X^{2}=7.0$ & $.024^{\star}$ \\
\hline Operating TV (NA=3) & $10(90.9 \%)$ & 35 (100\%) & 91 (100\%) & $136(97.1 \%)$ & $X^{2}=5.7$ & .080 \\
\hline Operating microwave (NA=5) & $7(70 \%)$ & $36(94.7 \%)$ & $85(97.7 \%)$ & $128(91.4 \%)$ & $x^{2}=9.0$ & $.010^{\star}$ \\
\hline Operating washing machine) (NA=8) & $7(70 \%)$ & $34(94.4 \%)$ & $83(96.5 \%)$ & $124(88.6 \%)$ & $X^{2}=7.6$ & $.016^{\star}$ \\
\hline Taking medication (NA=7) & 5 (55.6\%) & 38 (100\%) & 80 (93\%) & 123 (87.9\%) & $x^{2}=13.6$ & $<.001^{\star}$ \\
\hline Shopping (NA=3) & 7 (63.6\%) & 37 (100\%) & 84 (94.4\%) & $128(91.4 \%)$ & $x^{2}=12.1$ & $.002^{\star}$ \\
\hline
\end{tabular}

IADL were compared using Independent samples Pearson Chi-square Tests and Fisher Exact Tests. *Significance level set as p <.05.

*NA=Data either not available or not-applicable 
While ninety one participants in our study did not meet the criteria for dementia or MCI, they were found to have varying levels of cognitive and functional deficits. Cognitive impairment in the elderly exists on a continuum ranging from normal, subjective cognitive impairment (pre-MCI) ${ }^{42}$, MCI to dementia. In addition, impairment in multiple cognitive domains are present many years before a diagnosis of dementia (AD) is made. ${ }^{43}$ Even though the DSM criteria are widely used, the ICD-10 sets a higher threshold for dementia compared to DSM-III-R ${ }^{44}$ and a ten-fold difference in the rate of dementia diagnosis using six separate classification systems has been demonstrated. ${ }^{45}$ The literature has been criticised for failing to provide clear guidance on standards against which functional and cognitive impairments should be measured. ${ }^{32}$ Current diagnostic criteria define a 'narrow category of unambiguous dementia characterised by marked impairment'. ${ }^{46}$ The limitations of the current DSM IV-TR diagnostic system has the potential to under-estimate the prevalence of dementia with significant socio-clinical implications. ${ }^{47}$

Similar diagnostic challenges are encountered with MCI diagnosis. Different definitions of MCI have been shown to significantly influence the annual conversion rates from MCI to dementia. ${ }^{17} \mathrm{MCI}$ diagnosis requires the demonstration of the 'preservation of independence in functional abilities.' While abilities may appear to be overtly preserved, subtle impairments related to time and precision may be present that are not readily measurable ${ }^{29}$ and could still impact on the autonomy of individuals. In addition, consensus is required on the level of impairment in IADL that distinguishes MCI from dementia and normal ageing. ${ }^{33}$ These issues have significant clinical and ethical implications for clinicians, patients and their families

\section{Risk factors and dementia}

The prevalence of several clinical risk factors for cognitive impairment in our sample, compounded by the low level of protective factors, identifies this population as a vulnerable group in need of preventative interventions.

Demographic risk factors: In keeping with the literature, there was a progressive and statistically significant $(p=.020)$ increase in the mean age of participants from the MCI to Dementia categories in our study. The results also suggest an increasing progression of cognitive impairment with age. Increasing age has been identified as the 'most consistent risk factor for dementia worldwide'3,48 and for dementia in LAMIC countries. $.94,50,51$

In terms of gender, in our study, there were more than twice as many female participants ( 97 females, 43 males), and females were more prevalent in all diagnostic categories but the differences were non- significant. Our findings are similar to the Indo-US study ${ }^{52}$, where the prevalence of dementia was not associated with gender. Females have been shown to be at increased risk for dementia in developed regions as well as Asian countries, but this association was not clear for African and Latin American countries. ${ }^{3}$ Hormonal factors have been implicated in the differential risk of women ${ }^{53}$, however other protective factors may exist that are unique to women in developing countries; identification of such factors could be useful in reducing the risk to women in developed countries.

We were not able to show an association between race and the prevalence of cognitive impairment due to the low representation of Asians, blacks and coloureds in our sample (Table I). While trends are changing, it is not common local practice for the elderly to be placed in old-age homes, especially among Asian and black families, which may account for the low representation in our sample. Nigerian Africans have been found to have a lower prevalence of $\mathrm{AD}$ compared to their American-African counterparts. ${ }^{8}$ While different environmental risk factors may be implicated ${ }^{54}$, the clinical and molecular aetiologies of dementia have been found to differ among races ${ }^{55}$ contributing to racial differences in risk for the various types of dementia. It is therefore necessary for local studies to be conducted to establish the risk profile of the different race groups in South Africa.

Lastly, education is said to be protective against dementia through its contribution to cognitive reserve ${ }^{56}$ and our results indicated a significant difference in years of education between the MCI group compared to the dementia group. However, years of education may not be a sensitive measure of education in our sample where there are discrepancies in the quality of education received by different race groups. Two strategies are suggested to deal with education in this context, namely the use of literacy as a marker and the use of informants for screening of dementia. Literacy has been proposed as a more accurate measure of education. ${ }^{57}$ African Americans performed significantly lower than White Non-Hispanics on several cognitive tests despite controlling for demographics and years of education. These differences in performance disappeared after controlling for literacy levels ${ }^{58}$, highlighting the importance of accommodating for education effects when interpreting test results. It may be useful for local researchers to measure literacy as part of the assessment of dementia in future. The second strategy of using informant surveys may offer an opportunity to overcome the challenges posed in assessments due to differences in educational level. The use of informants in cognitive evaluations has been shown in different cultures to be as effective as cognitive assessments and has the advantage of not being biased by educational level. .9,60 $^{6}$ Unfortunately in our studywe did not have access to informants.

Clinical risk factors: Described as a 'tidal wave on the horizon ${ }^{61}$, dementia in LAMICs has been shown to be the most important independent contributor to disability in the elderly. ${ }^{62}$ In the absence of specific treatment, attention has to be focussed on identifying and modifying risk factors. Optimum and aggressive control of hypertension, diabetes, weight, smoking, and vascular risk factors and the need for exercise have been identified as potential preventative strategies. ${ }^{63,64}$

Vascular dementia accounts for about $30 \%$ of the total dementia prevalence. ${ }^{3}$ Vascular risk factors were most prevalent in our study. The history of a stroke among the dementia cases (36.4\%) was high even though this did not reach statistical significance. There was also radiological evidence of vascular pathology in all six of the dementia participants for whom scans were available, three of whom had evidence of infarcts. Temporality was not established in our study, but it is known that $10 \%$ of patients develop dementia after a first stroke and a third after recurrent stroke. ${ }^{65}$ The acute stroke patient of today, may be the dementia referral of tomorrow. There is therefore a need for stroke neurologists and cognitive physicians to work more closely ${ }^{63}$, to ensure optimum management of this high risk population and early detection of cognitive impairment. 
Hypertension was present in $66.4 \%$ of the participants: $36.4 \%$ in dementia, $57.9 \%$ in MCI and $73.6 \%$ in the non-case group, $\mathrm{p}=.024$. This represents a high burden and raises concern as hypertension has been associated with an increased risk of cognitive decline and dementia $29,66,67,3$ as well as a higher rate of progression from MCI to dementia. ${ }^{58}$ While there is no compelling evidence that dementia can be prevented by modifying vascular risk factors ${ }^{68}$, a more complete understanding of the pathophysiology, and aetiology of dementia, especially in different population groups $s^{3,68,69}$, will serve to better inform clinicians. Optimum management of vascular disease is nonetheless necessary for healthy ageing. ${ }^{68}$ Diabetes, also shown to increase the risk of dementia in the elderly ${ }^{70-60}$, was not significantly more prevalent in the dementia group compared to the MCI and 'non-case' groups. 36.5\%, $212.1 \%, 27.5 \%$; $\mathrm{p}=.530$ ). However, low dementia case numbers $(<4)$ also prevent us identifying diabetes as being associated with dementia in our sample. A fifth (21.1\%) of those diagnosed with MCI in our study had diabetes mellitus, identifying them at higher risk, as diabetes has been shown to substantially increase the progression from MCI to dementia. ${ }^{71}$

Physical and mental exercise, social engagement, and nutrition and stress management are important factors in maintaining cognitive vitality and protecting against the development of dementia. ${ }^{72}$ A comprehensive review of the evidence has also confirmed the negative impact of social isolation and the protective effect of exercise on cognitive health. ${ }^{73}$ Of concern in our study was the fact that the participants were found to be physically inactive with less than a quarter of participants engaging in any physical exercise. Given the significant medical implications of a sedentary life, this is an important and simple intervention that can reduce risk for both physical and cognitive decline.

Subjective memory complaints: More than 50\% of our sample reported the presence of a subjective memory complaint. A significant association was found between the presence of a SMC and the presence of dementia $\left(\mathrm{X}^{2}=51.6\right.$, $\mathrm{p}=.001$ ). In our study, a SMC was present in $90.9 \%$ of those diagnosed with dementia. The prevalence of SMC in the community varies from $25-50 \%^{74}$ and is present in $42.8 \%$ of dementia sufferers and $38.2 \%$ with MCI. ${ }^{75}$ As with any subjective measure, assessing for the presence of SMCs poses challenges. The lack of standardisation of the definition of SMCs across studies complicates the interpretation of results $\mathrm{as}^{31}$ different criteria may refer to different underlying cognitive constructs. However, the presence of SMC has been associated with cerebral white matter lesions in the absence of objective cognitive impairment ${ }^{76}$, implying that they may have diagnostic validity. The diagnosis of SMC should therefore be standardised based on criteria that include age and nature of onset, course, duration and frequency. ${ }^{31}$ This may result in better correlation between subjective and objective measures of disease and improve the validity and predictive value of SMCs for dementia.

The mean number of memory complaints per participant in our study increased significantly with increasing cognitive impairment from MCI to Dementia ( $p=.001)$. The presence of subjective memory complaints (SMC), also referred to as subjective memory impairment (SMI), and subjective cognitive impairment (SCI), is regarded as a pre-MCI stage which has a mean duration of 15 years. ${ }^{42}$ Elderly individuals with SMC may be at a fourfold increase of dementia or a two fold increase of depression. ${ }^{71}$ However, an association between SMC and depression, past or current, was not found in our study.

The utility index of SMC has recently been assessed as 'good' for ruling out a diagnosis of dementia but 'poor' for ruling in a diagnosis of dementia as there is only a 20\%-30\% chance of dementia or MCI being present in those with SMC. ${ }^{75}$ However, there is evidence for its use in brief screening programmes. ${ }^{75}$ In the local context of a severe shortage of mental health professionals ${ }^{78}$, further evaluation of the clinical correlates and utility of SMCs may clarify its potential as a simple, cost-effective screening measure towards meeting the challenges associated with the predicted upsurge in the prevalence of dementia.

Functional assessments: A diagnosis of dementia requires the confirmation of cognitive decline of sufficient severity to cause functional impairment. The concise definition of the functional status of patients is necessary for optimum care planning ${ }^{79}$ as greater impairment has been associated with earlier institutionalization, decreased quality of life, death, increased caregiver burden, and increased health and care costs. ${ }^{80}$

In the current study, the preservation of activities of daily living (IADL) functions in the dementia category ranged from $40 \%$ for the independent use of public transport to $90.9 \%$ for the use of a telephone. With the exception of the ability to use a telephone and the television, preservation of functionality in the remaining IADL domains assessed significantly distinguished those with dementia from those without (Table III). In our sample, the use of the telephone was an ability that was best preserved amongst all diagnostic categories, suggesting that this might be an ability that is relatively resistant to deterioration. Inter-task difference analyses have revealed that finances, meal preparation, housekeeping and shopping are the earliest functions to deteriorate, while telephone use appeared to be more resistant. ${ }^{80}$ Loss of skills related to independent medication management, shopping, housekeeping and use of public transport have also been shown to significantly impact on time to incident dementia. ${ }^{35}$

In LAMIC, where low education levels are more prevalent than in HIC, screening tools with minimal education bias are necessary. Cognitive decline contributes to functional impairment and is expressed among instrumental activities before basic activities of daily living. ${ }^{80}$ IADL require a high degree of executive skills and executive dysfunction has been correlated with IADL disability. ${ }^{79}$ Functional scales therefore have the potential to be used as screening tools, and have less education bias than cognitive tests. ${ }^{81}$ Several IADL scales are in use and even though their psychometric properties need to be further established ${ }^{82}$, they have been shown to discriminate between the demented and non-demented as well as detect mild dementia with minimum effects of age, gender and education. ${ }^{81}$

IADL scales have been shown to be 'reliable, sensitive and responsive' and useful in dementia screening in a heterogeneous Indian population ${ }^{83}$, with acceptable efficiency for dementia screening. ${ }^{84}$ They have been shown to compare favourably against the MMSE when administered by General Practitioners and have the advantage of being simple and nonthreatening to administer. ${ }^{85}$

It has been shown that subjects who performed poorly on 
IADL were more likely to develop dementia ten years later. ${ }^{33}$ IADL assessments are useful as diagnostic aids in memory clinics, and are able to predict the onset of dementia at one and two year follow-up. ${ }^{86} \mathrm{IADL}$ assessments also have the potential to distinguish between clinical stages along the continuum from subjective to objective cognitive impairment. Specific areas of IADL impairment show discriminative and predictive power for Subjective Cognitive Impairment (SCI) and MCI. ${ }^{87}$ The inclusion of IADL impairment in the diagnosis of MCI has been shown to significantly improve dementia prediction in those who have MCI. ${ }^{35}$ These findings support the need for the further evaluation of IADL scales as screening tools for dementia in the local setting especially as they require low skill in administration. The limitations of IADL scales can be addressed by enhancing self-report through collateral corroboration $^{86}$, standardizing performance-based assessments that include measures of accuracy and speed ${ }^{35}$, and improving the psychometric properties by establishing validity.

\section{Limitations}

While this study provides useful information on the demographic and risk profile of a heterogeneous South African elderly population, the nature of the sample and its small size, the low numbers of black participants, and the low number of dementia cases limit the generalizability of our findings. Interrater reliability should have been formally quantified. The study is however useful in defining the risk profile of this elderly population and provides a platform for the introduction of risk management interventions.

\section{Conclusion}

The quantification of the prevalence of cognitive impairment in a non-clinical sample highlights its under-recognition locally. The prevalent risk factors call for increasing the awareness of dementia in the general population combined with active medical outreach to non-clinical populations. The reported lower prevalence of dementia in LAMIC highlights the need for risk factors as well as 'protective' social and contextual determinants of health and dementia, the 'new epidemiology'88, to be studied. Dementia in LAMICs deserve further epidemiological research to address the growing burden ${ }^{89}$, better define risks and devise novel approaches to prevention, early detection and adequate treatment. ${ }^{33}$

\section{Acknowledgments}

The authors would like to thank Drs V Moodley and A Porter for their assistance in the clinical assessments of participants.

\section{References}

1. Ferri CP, Prince M, Brayne C, Brodaty H, Fratiglioni L, Ganguli M, et al. Global prevalence of dementia: a Delphi consensus study. Lancet 2005;366 (9503):2112-7.

2. Wimo A, Winblad B, Jonsson L. An estimate of the total worldwide societal costs of dementia in 2005. Alzheimer's \& dementia : the journal of the Alzheimer's Association 2007;3(2):81-91.

3. Kalaria RN, Maestre GE, Arizaga R, Friedland RP, Galasko D, Hall K, et al. Alzheimer's disease and vascular dementia in developing countries: prevalence, management, and risk factors. Lancet neurology 2008;7(9):812-26.

4. Prince M, Bryce R, Ferri C. World Alzheimer Report 2011: The
Benefits of Early Diagnosis and Treatment. Alzheimer's Disease International, 2011.

5. Fratiglioni L, De Ronchi D, Aguero Torres H. Worldwide Prevalence and Incidence of Dementia. Drugs and Aging 1999; 15(5):365-75.

6. Jorm AF KA, Henderson AS. The prevalence of dementia: $A$ quantitative integration of the literature. Acta psychiatrica Scandinavica 1987;76(5):465-79.

7. Llibre Rodriguez JJ, Ferri CP, Acosta D, Guerra M, Huang Y, Jacob KS, et al. Prevalence of dementia in Latin America, India, and China: a population-based cross-sectional survey. Lancet 2008;372(9637):464-74.

8. Hendrie HC, Osuntokun BO, Hall KS, Ogunniyi AO, Hui SL, Unverzagt $F W$, et al. Prevalence of Alzheimer's disease and dementia in two communities: Nigerian Africans and African Americans. The American journal of psychiatry 1995;152(10):1485-92.

9. Chandra V, Ganguli M, Pandav R, Johnston J, Belle S, DeKosky ST. Prevalence of Alzheimer's disease and other dementias in rural India: the Indo-US study. Neurology 1998;51 (4):1000-8.

10. Ineichen B. The epidemiology of dementia in Africa: a review. Soc Sci Med 2000;50(11):1673-7.

11. Guerchet M, Houinato D, Paraiso MN, von Ahsen N, Nubukpo P, Otto $M$, et al. Cognitive impairment and dementia in elderly people living in rural Benin, west Africa. Dementia and geriatric cognitive disorders 2009;27(1):34-41

12. Farrag A, Farwiz HM, Khedr EH, Mahfouz RM, Omran SM. Prevalence of Alzheimer's disease and other dementing disorders: Assiut-Upper Egypt study. Dementia and geriatric cognitive disorders 1998;9(6):323-8.

13. Guerchet M, M'Belesso P, Mouanga AM, Bandzouzi B, Tabo A, Houinato DS, et al. Prevalence of dementia in elderly living in two cities of Central Africa: the EDAC survey. Dementia and geriatric cognitive disorders 2010;30(3):261-8.

14. Ben-Arie O, Swartz L, Teggin AF, Elk R. The coloured elderly in Cape Town--a psychosocial, psychiatric and medical community survey. Part II. Prevalence of psychiatric disorders. South African medical journal = Suid-Afrikaanse tydskrif vir geneeskunde 1983;64(27):1056-61.

15. Van der Poel R, Heyns PM. Algorithmic case prediction in relation to local clinician diagnosis in an indigenous South African population. 27th International Conference of Alzheimer's Disease International (ADI). London, England, 2012

16. American Psychiatric Association. Diagnostic and Statistical Manual of Mental Disorders-Text Revision. 4th ed: American Psychiatric Publishing, Inc., 2000

17. Winblad B, Palmer K, Kivipelto M, Jelic V, Fratiglioni L, Wahlund LO, et al. Mild cognitive impairment--beyond controversies, towards a consensus: report of the International Working Group on Mild Cognitive Impairment. Journal of internal medicine 2004;256(3):240-6.

18. Petersen RC. Mild Cognitive Impairment. Continuum 2004;10:9-28.

19. Guo M, Gao L, Zhang G, Li Y, Xu S, Wang Z, et al. Prevalence of dementia and mild cognitive impairment in the elderly living in nursing and veteran care homes in Xi'an, China. Journal of the neurological sciences 2012;312(1-2):39-44

20. Cheng ST, Lam LC, Chow PK. Under-recognition of dementia in longterm care homes in Hong Kong. Aging \& mental health 2012;16(4):516-20.

21. Lithgow S, Jackson GA, Browne D. Estimating the prevalence of dementia: cognitive screening in Glasgow nursing homes. International journal of geriatric psychiatry 2012;27(8):785-91.

22. Cherubini A, Ruggiero C, Dell'aquila G, Eusebi P, Gasperini B, Zengarini $E$, et al. Underrecognition and Undertreatment of 
Dementia in Italian Nursing Homes. Journal of the American Medical Directors Association 2012

23. Mann AH, Graham N, Ashby D. Psychiatric illness in residential homes for the elderly: a survey in one London borough. Age and ageing 1984;13(5):257-65.

24. Mathews FE, Dening T. Prevalence of dementia in institutional care. The Lancet 2002;360:225-26.

25. Alvarado-Esquivel C, Hernandez-Alvarado AB, Tapia-Rodriguez RO, Guerrero-Iturbe A, Rodriguez-Corral K, Martinez SE. Prevalence of dementia and Alzheimer's disease in elders of nursing homes and a senior center of Durango City, Mexico. BMC psychiatry 2004;4:3

26. Ward A, Arrighi HM, Michels S, Cedarbaum JM. Mild cognitive impairment: disparity of incidence and prevalence estimates. Alzheimer's \& dementia : the journal of the Alzheimer's Association 2012;8(1):14-21

27. Petersen RC, Smith GE, Waring SC. Mild Cognitive Impairment. Clinical Characterization and Outcome. Archives of neurology 1999;56:303-08.

28. Sachdev PS, Lipnicki DM, Crawford J, Reppermund S, Kochan NA, Trollor JN, et al. Risk profiles of subtypes of mild cognitive impairment: the sydney memory and ageing study. Journal of the American Geriatrics Society 2012;60(1):24-33.

29. Albert MS, DeKosky ST, Dickson D, Dubois B, Feldman HH, Fox NC, et al. The diagnosis of mild cognitive impairment due to Alzheimer's disease: recommendations from the National Institute on AgingAlzheimer's Association workgroups on diagnostic guidelines for Alzheimer's disease. Alzheimer's \& dementia : the journal of the Alzheimer's Association 2011;7(3):270-9.

30. Luis CA, Loewenstein DA, Acevedo A, Barker WW, Duara R. Mild cognitive impairment: directions for future research. Neurology 2003;61(4):438-44

31. Abdulrab K, Heun R. Subjective Memory Impairment. A review of its definitions indicates the need for a comprehensive set of standardised and validated criteria. European psychiatry : the journal of the Association of European Psychiatrists 2008;23(5):321-30.

32. Royall DR. Mild Cognitive Impairment and Functional Status. Journal of American Geriatrics Society 2005;54(1):163-65.

33. Peres K, Helmer C, Amieva H, Orgogozo JM, Rouch I, Dartigues JF, et al. Natural history of decline in instrumental activities of daily living performance over the 10 years preceding the clinical diagnosis of dementia: a prospective population-based study. Journal of the American Geriatrics Society 2008;56(1):37-44.

34. Han JW, Lee SB, Kim TH, Park JH, Lee JJ, Huh YS, et al. Functional impairment in the diagnosis of mild cognitive impairment. Alzheimer disease and associated disorders 201 1;25(3):225-9.

35. Luck T, Luppa M, Wiese B, Maier W, van den Bussche H, Eisele $M$, et al. Prediction of Incident Dementia: Impact of Impairment in Instrumental Activities of Daily Living and Mild Cognitive Impairment-Results From the German Study on Ageing, Cognition, and Dementia in Primary Care Patients. The American journal of geriatric psychiatry : official journal of the American Association for Geriatric Psychiatry 2012

36. Petersen RC, Stevens JC, Ganguli EG. Practice parameter: Early detection of dementia: Mild cognitive impairment ( an evidencebased review) : Report of the Quality Standards Subcommittee of the American Academy of Neurology. Neurology 2001;56(9):1 133-42.

37. Nordlund A, Rolstad S, Gothlin M, Edman A, Hansen S, Wallin A. Cognitive profiles of incipient dementia in the Goteborg MCI study. Dementia and geriatric cognitive disorders 2010;30(5):403-10.

38. Hughes TF, Snitz BE, Ganguli M. Should mild cognitive impairment be subtyped? Current opinion in psychiatry 201 1;24:237-42.

39. Nordlund A, Rolstad S, Hellstrom P, Sjogren M, Wallin A. The Goteborg MCI study: mild cognitive impairment is a heterogeneous condition. Journal of Neurology, Neurosurgery and Psychiatry 2005;76:1485-90.

40. Mathew R, Mathuranath PS. Issues in evaluation of cognition in the elderly in developing countries. Annals of Indian Academy of Neurology 2008;1 1 (2):82-8.

41. Chandra V, Ganguli M, Ratcliff G, Pandav R, Sharma S, Belle S, et al. Practical issues in cognitive screening of elderly illiterate populations in developing countries. The Indo-US Cross-National Dementia Epidemiology Study. Aging (Milano) 1998;10(5):349-57.

42. Reisberg B, Gauthier S. Current evidence for subjective cognitive impairment (SCI) as the pre-mild cognitive impairment (MCI) stage of subsequently manifest Alzheimer's disease. International psychogeriatrics / IPA 2008;20(1):1-16.

43. Backman L, Jones S, Berger AK, Laukka EJ, Small BJ. Multiple cognitive deficits during the transition to Alzheimer's disease. Journal of internal medicine 2004;256(3):195-204.

44. Riedel-Heller SG, Busse A, Aurich C, Matschinger H, Angermeyer MC. Prevalence of dementia according to DSM-III-R and ICD-10: results of the Leipzig Longitudinal Study of the Aged (LEILA75+) Part 1. The British journal of psychiatry : the journal of mental science 2001;179:250-4

45. Erkinjuntti T, Ostbye T, Steenhuis R, Hachinski V. The effect of different diagnostic criteria on the prevalence of dementia. The New England journal of medicine 1997;337(23):1667-74.

46. Prince MJ, de Rodriguez JL, Noriega L, Lopez A, Acosta D, Albanese $E$, et al. The 10/66 Dementia Research Group's fully operationalised DSM-IV dementia computerized diagnostic algorithm, compared with the 10/66 dementia algorithm and a clinician diagnosis: a population validation study. BMC public health 2008;8:219

47. Husaini BA, Sherkat DE, Moonis M, Levine R, Holzer C, Cain VA. Racial Differences in the Diagnosis of Dementia and in Its Effects on the Use and Costs of Health Care Services Psychiatric Services 2003;54:92-96.

48. Jorm AF, Korten AE, Henderson AS. The prevalence of dementia: a quantitative integration of the literature. Acta psychiatrica Scandinavica 1987;76(5):465-79.

49. Gureje O, Ogunniyi A, Kola L, Abiona T. Incidence of and risk factors for dementia in the Ibadan study of aging. Journal of the American Geriatrics Society 2011;59(5):869-74.

50. Toure K, Coume M, Sow PG, Ndiaye NND, Basse A, Diagne N, et al. Prevalence of dementia varied with age,education and social network in Senegalese elderly population of patients utilizing the Medico-Social and University Centre of IPRES, Dakar-Senegal. International Journal of Medicine and Medical Sciences 2012;4(2):33-38.

51. Yusuf AJ, Baiyewu O, Sheikh TL, Shehu AU. Prevalence of dementia and dementia subtypes among community-dwelling elderly people in northern Nigeria. International psychogeriatrics / IPA 2011;23(3):379-86.

52. Chandra V GM, Pandav R, et al. Prevalence of Alzheimer's Disease and other dementias in rural India. Neurology 1998;51 (4):1000-8.

53. Mc Cullagh CD, Craig D, Mcllroy SP, Passmore AP. Risk factors for dementia. Advances in Psychiatric Treatment 2001;7:24-31.

54. Manly JJ, Mayeux R, editors. Ethnic Differences in Dementia and Alzheimer's Disease 95. Washington, D.C.: The National Academies Press, 2004.

55. Froehlich TE, Bogardus ST, Jr., Inouye SK. Dementia and race: are there differences between African Americans and Caucasians? 
Journal of the American Geriatrics Society 2001;49(4):477-84.

56. Ngandu T, von Strauss E, Helkala EL, Winblad B, Nissinen A, Tuomilehto J, et al. Education and dementia: what lies behind the association? Neurology 2007;69(14):1442-50

57. Pittman J, Andrews H, Tatemichi T, Link B, Struening E, Stern Y, et al. Diagnosis of dementia in a heterogeneous population. A comparison of paradigm-based diagnosis and physician's diagnosis. Archives of neurology 1992;49(5):461-7.

58. Chin AL, Negash S, Xie S, Arnold SE, Hamilton R. Quality, and not just quantity, of education accounts for differences in psychometric performance between african americans and white non-hispanics with Alzheimer's disease. Journal of the International Neuropsychological Society : JINS 2012;18(2):277-85

59. Jorm AF, Scott R, Cullen JS, MacKinnon AJ. Performance of the Informant Questionnaire on Cognitive Decline in the Elderly (IQCODE) as a screening test for dementia. Psychological medicine 1991;21 (3):785-90

60. Ritchie K, Fuhrer R. A comparative study of the performance of screening tests for senile dementia using receiver operating characteristics analysis. J Clin Epidemiology 1992;45(6):627-37.

61. Sabat SR. Dementia in developing countries; a tidal wave on the horizon. The Lancet 2009;374(Nov 28):1805-06.

62. Sousa RM, Ferri CP, Acosta D, Albanese E, Guerra M, Huang Y, et al. Contribution of chronic diseases to disability in elderly people in countries with low and middle incomes: a 10/66 Dementia Research Group population-based survey. Lancet 2009;374(9704):1821-30.

63. Cumming T, Brodtmann A. Dementia and stroke: the present and future epidemic. International journal of stroke : official journal of the International Stroke Society 2010;5(6):453-4.

64. Wilson D, Ritchie K, Peters R, Ritchie CW. Latest advances on interventions that may prevent, delay or ameliorate dementia. Therapeutic Advances in Chronic Diseases 2011;2(3):161-73.

65. Pendlebury ST, Rothwell PM. Prevalence, incidence, and factors associated with pre-stroke and post-stroke dementia: a systematic review and meta-analysis. Lancet neurology 2009;8(11):1006-18.

66. Qiu C, Winblad B, Fratiglioni L. The age-dependent relation of blood pressure to cognitive function and dementia. Lancet neurology 2005;4(8):487-99.

67. Ogunniyi A, Lane KA, Baiyewu O, Gao S, Gureje O, Unverzagt FW, et al. Hypertension and incident dementia in community-dwelling elderly Yoruba Nigerians. Acta neurologica Scandinavica 2011;124(6):396-402.

68. Stephan BC, Brayne C. Vascular factors and prevention of dementia. Int Rev Psychiatry 2008;20(4):344-56.

69. Purandare N. Prevention of dementia: Role of vascular risk factors and cerebral emboli. Indian journal of psychiatry 2009;51 Suppl 1:S39-43

70. Peila R, Rodriguez BL, Launer LJ. Type 2 diabetes, APOE gene, and the risk for dementia and related pathologies: The Honolulu-Asia Aging Study. Diabetes 2002;51 (4):1256-62.

71. Xu W, Caracciolo B, Wang HX, Winblad B, Backman L, Qiu C, et al. Accelerated progression from mild cognitive impairment to dementia in people with diabetes. Diabetes 2010;59(11):2928-35.

72. Fillit HM, Butler RN, O'Connell AW, Albert MS, Birren JE, Cotman CW, et al. Achieving and maintaining cognitive vitality with aging. Mayo Clinic proceedings. Mayo Clinic 2002;77(7):681-96.

73. John W. Williams, Brenda L. Plassman, James Burke, Tracey Holsinger, Benjamin. S. Preventing Alzheimer's Disease and Cognitive Decline Evidence Report/Technology Assessment Durham, North Carolina Duke Evidence-based Practice Center 2010.

74. Jonker C, Geerlings MI, Schmand B. Are memory complaints predictive for dementia? A review of clinical and population-based studies. International journal of geriatric psychiatry

2000;15(11):983-91.

75. Mitchell AJ. The clinical significance of subjective memory complaints in the diagnosis of mild cognitive impairment and dementia: a metaanalysis. International journal of geriatric psychiatry 2008;23(11):1191-202.

76. de Groot JC, de Leeuw FE, Oudkerk M, Hofman A, Jolles J, Breteler MM. Cerebral white matter lesions and depressive symptoms in elderly adults. Archives of general psychiatry 2000;57(11):1071-6.

77. Tobiansky R, Blizard R, Livingston G, Mann A. The Gospel Oak Study stage IV: the clinical relevance of subjective memory impairment in older people. Psychological medicine 1995;25(4):779-86.

78. Burns JK. Mental health services funding and development in KwaZulu-Natal: a tale of inequity and neglect. South African medical journal $=$ Suid-Afrikaanse tydskrif vir geneeskunde 2010;100(10):662-6.

79. Desai AK, Grossberg GT, Sheth DN. Activities of daily living in patients with dementia: clinical relevance, methods of assessment and effects of treatment. CNS drugs 2004;18(13):853-75.

80. Jefferson AL, Paul RH, Ozonoff A, Cohen RA. Evaluating elements of executive functioning as predictors of instrumental activities of daily living (IADLS). Archives of clinical neuropsychology : the official journal of the National Academy of Neuropsychologists 2006;21 (4):311-20.

81. Juva K, Makela M, Erkinjuntti T, Sulkava R, Ylikoski R, Valvanne J, et al. Functional assessment scales in detecting dementia. Age and ageing 1997;26(5):393-400

82. Sikkes SA, de Lange-de Klerk ES, Pijnenburg YA, Scheltens $P$, Uitdehaag BM. A systematic review of Instrumental Activities of Daily Living scales in dementia: room for improvement. Journal of neurology, neurosurgery, and psychiatry 2009;80(1):7-12.

83. Mathuranath PS, George A, Cherian PJ, Mathew R, Sarma PS. Instrumental activities of daily living scale for dementia screening in elderly people. International psychogeriatrics / IPA 2005; 17(3):461-74.

84. Castilla-Rilo J, Lopez-Arrieta J, Bermejo-Pareja F, Ruiz M, SanchezSanchez F, Trincado R. Instrumental activities of daily living in the screening of dementia in population studies: a systematic review and meta-analysis. International journal of geriatric psychiatry 2007;22(9):829-36.

85. De Lepeleire J, Aertgeerts B, Umbach I, Pattyn P, Tamsin F, Nestor L, et al. The diagnostic value of IADL evaluation in the detection of dementia in general practice. Aging \& mental health 2004;8(1):52-7.

86. Sikkes SA, Visser PJ, Knol DL, de Lange-de Klerk ES, Tsolaki M, Frisoni $G B$, et al. Do instrumental activities of daily living predict dementia at 1- and 2-year follow-up? Findings from the Development of Screening guidelines and diagnostic Criteria for Predementia Alzheimer's disease study. Journal of the American Geriatrics Society 2011;59(12):2273-81.

87. Yoon B, Shim YS, Hong YJ, Kim YD, Lee KO, Na SJ, et al. Which symptoms can distinguish between subjective cognitive impairment (SCI) and mild cognitive impairment (MCI)? Archives of gerontology and geriatrics 2012;54(2):325-9.

88. McDowell I. From counting to understanding: the evolving epidemiologic approach to dementia. Canadian journal of psychiatry. Revue canadienne de psychiatrie 2004;49(2):81-2.

89. Prince M, Acosta D, Albanese E, Arizaga R, Ferri CP, Guerra M, et al. Ageing and dementia in low and middle income countries-Using research to engage with public and policy makers. Int Rev Psychiatry 2008;20(4):332-43. 